\title{
DIVERGÊNCIA GENÉTICA ENTRE PROGÊNIES DE MARACUJAZEIRO- AMARELO COM BASE EM CARACTERÍSTICAS DAS PLÂNTULAS ${ }^{1}$
}

\author{
JACSON RONDINELLIDA SILVANEGREIROS ${ }^{2}$, RODRIGO SOBREIRAALEXANDRE ${ }^{3}$, VIRGÍNIADE SOUZAÁLVARES ${ }^{4}$, \\ CLAUDIO HORST BRUCKNER ${ }^{5}$, COSME DAMIÃO CRUZ ${ }^{5}$
}

RESUMO - O objetivo do presente trabalho foi avaliar a diversidade genética entre 24 populações de maracujazeiro-amarelo, discriminando os caracteres mais importantes na avaliação da divergência genética, com base em características das plântulas. Foram coletadas sementes de frutos obtidos a partir de polinização natural de vinte e quatro populações segregantes de meios-irmãos de maracujazeiro-amarelo. Utilizou-se delineamento experimental inteiramente casualizado, em vinte e quatro tratamentos (populações segregantes), com quatro repetições, considerando-se como unidade experimental cada grupo de 50 sementes. Aos 28 dias, avaliaramse a porcentagem de germinação e o índice de velocidade de emergência (IVE). Aos 45 dias, avaliaram-se porcentagem de sobrevivência, altura das plântulas, comprimento de raiz, número de folhas e massa da matéria seca total das plântulas. Os dados obtidos foram submetidos à análise de variância, e as médias foram agrupadas pelo método de Scott \& Knott. A diversidade genética foi estudada de acordo com o método de agrupamento de Tocher, baseado na distância de Mahalanobis $\left(\mathrm{D}^{2}\right)$ e variáveis canônicas. As características que mais contribuíram para a divergência genética foram porcentagem de germinação, número de folhas e IVE. A população 20 pode ser recomendada para hibridação com as outras populações devido à sua alta divergência e também altas taxas de germinação e vigor de sementes.

Termos para indexação: divergência genética, Passiflora edulis f. flavicarpa, germinação.

\section{GENETIC DIVERGENCE AMONG YELLOW PASSION FRUIT PROGENIES BASED ON SEED TRAITS}

\begin{abstract}
The genetic diversity was studied among passion fruit (Passiflora edulis f. flavicarpa) progenies, discriminating the characters most important of seed traits for genetic divergence evaluation. Seeds were extracted of fruits gotten by natural pollination of twenty four half-sib segregant populations. The experiment was outlined as an entirely randomized design with twenty four treatments (segregant populations), four replications and 50 seeds per experimental unit. The germination percentage and the Speed Germination Index (IVE) were evaluated after 28 days and the seedling height and survival percentage, root length, leaf number and total dry weight of the seedlings were evaluated after 45 days. The data were submitted to the variance analysis and the means were grouped according to Scott \& Knott method. Genetic diversity was studied according to Tocher's grouping method based in Mahalanobis distance $\left(\mathrm{D}^{2}\right)$ and canonical variables. The traits that had contributed more for the genetic divergence were percentage of germination, leaf number and IVE. Population 20 can be recommended for crossing with the other populations due to its high divergence and high germination rates and seed vigor.
\end{abstract}

Index Terms: genetic divergence, Passiflora edulis f. flavicarpa, germination.

\section{INTRODUÇÃO}

A cultura do maracujazeiro é apreciada tanto pela qualidade de seus frutos, ricos em sais minerais e vitaminas, sobretudo A e C, possuindo suco com aroma e sabor bastante agradáveis, quanto pelas propriedades farmacológicas (Lima, 2002). O caráter social da cultura do maracujá é de grande relevância, já que é uma fruteira cultivada predominantemente em pequenos pomares, em média de 1 a 4 ha, promovendo a geração de empregos, a absorção e a fixação de mão-de-obra no meio rural (Souza et al., 2002).

No Brasil, a espécie mais importante, tanto para o consumo in natura como para processamento, é Passiflora edulis $\mathrm{f}$. flavicarpa, maracujá-amarelo ou azedo (Cunha et al., 2002). Quanto à germinação de sementes de maracujazeiro-amarelo, o início e o término ocorrem de forma irregular, podendo, este período, ser de dez dias a três meses, o que dificulta a formação das mudas, por não serem uniformes (Akamine et al., 1956; Luna, 1984).

A qualidade fisiológica das sementes é influenciada pelo genótipo, sendo máxima na sua maturidade. Prete \& Guerra (1999) também consideram que o máximo potencial de qualidade das sementes, como germinação, emergência e vigor de plântulas, possa ser controlado geneticamente. Alexandre et al. (2004) verificaram que a germinação e a velocidade de emergência em maracujazeiro são influenciados pelo genótipo das sementes.

A divergência genética é um dos mais importantes

(Trabalho 086-07). Recebido em: 28-03-2007. Aceito para publicação em: 20-09-2007.

${ }^{2}$ Bolsista DRC/CNPq, Universidade Federal do Acre, UFAC. Rio Branco - AC. CEP 69915-900. e-mail: jacsonrn@gmail.com

${ }^{3}$ Pós-Doutorando, Departamento de Fitotecnia, UFV. Viçosa - MG, CEP 36570-000. e-mail: rsalexandre@click21.com.br

${ }^{4}$ Bolsista DRC/CNPq, Embrapa Acre, Rio Branco - AC. CEP 69908-970. e-mail: virginia@cpafac.embrapa.br.

${ }^{5}$ Professor da Universidade Federal de Viçosa, Viçosa - MG, CEP - 36570-000. e-mail: bruckner@ufv.br, cdcruz@ufv.br 
parâmetros avaliados por melhoristas de plantas na fase inicial de um programa de melhoramento genético. Em programas que envolvem hibridações, estes estudos fornecem parâmetros para identificação de genitores que, quando cruzados, possibilitam maior efeito heterótico na progênie (Samal \& Jagadev, 1996; Pandey \& Dobhal, 1997; Carvalho et al., 2003).

Nos estudos de melhoramento genético de plantas, principalmente em programas de seleção, a diversidade genética pode ser investigada precocemente pela qualidade fisiológica das sementes, com os testes de vigor (Dias \& Marcos Filho, 1995). Assim, o tempo médio de germinação e a sua uniformidade poderão proporcionar produção de mudas em escala comercial de maneira mais eficiente.

Este trabalho teve como objetivo avaliar a diversidade genética entre as 24 populações de maracujazeiro-amarelo estudadas por Alexandre et al. (2004), discriminando os caracteres mais importantes na avaliação da divergência genética de característica na semente com base em procedimentos multivariados.

\section{MATERIAL E MÉTODOS}

Os trabalhos foram realizados no Setor de Fruticultura do Departamento de Fitotecnia, da Universidade Federal de ViçosaMG, no período de junho a setembro de 2003, com sementes extraídas de frutos maduros e bem desenvolvidos de maracujazeiro-amarelo (P. edulis Sims f. flavicarpa).

$\mathrm{Na}$ extração das sementes, os frutos foram seccionados pela metade, retirando-se de sua cavidade interna a mucilagem que continha as sementes. A retirada do arilo foi realizada manualmente, por meio de fricção em peneira de malha fina, acrescentando-se cal virgem. Após a remoção, as sementes foram lavadas em água corrente e dispostas em papel toalha, onde permaneceram durante três dias, à sombra, para secagem. Em seguida, foram semeadas a uma profundidade de $0,5 \mathrm{~cm}$, em

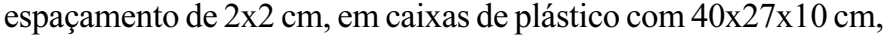
contendo como substrato uma mistura de terra vermelha: areia $(1: 1 \mathrm{v} / \mathrm{v})$. As caixas foram dispostas em uma mesa de ripado suspensa, sob tela sombrite com $70 \%$ de incidência solar.

Foram coletadas sementes de 03 frutos de cada planta, representando as populações obtidas a partir de polinização natural de vinte e quatro populações segregantes de meiosirmãos de maracujazeiro-amarelo, no período de junho a julho de 2003, cuja ascendência e procedência estão descritas na Tabela 1. O delineamento experimental foi inteiramente casualizado, com vinte e quatro tratamentos (populações segregantes) e quatro repetições, considerando-se como uma unidade experimental cada grupo de 50 sementes, totalizando 200 sementes por tratamento. A temperatura média do ar foi de $16,1^{\circ} \mathrm{C}$, variando entre $13,5^{\circ} \mathrm{C}$ e $20,2^{\circ} \mathrm{C}$.

Aos 28 dias, avaliaram-se a porcentagem de germinação e o índice de velocidade de emergência (IVE) (Maguire, 1962). Aos 45, dias foram avaliados a porcentagem de sobrevivência de plântulas após a germinação (\%), a altura das plântulas $(\mathrm{cm})$, o comprimento de raiz $(\mathrm{cm})$, o número de folhas e a massa da matéria seca total das plântulas $(\mathrm{mg})$. Os dados das porcentagens de germinação e de sobrevivência foram transformados em arcoseno $\sqrt{x / 100}$, e o número de folhas, em $\sqrt{x+1}$. Os dados das demais variáveis não sofreram transformação. O IVE foi estabelecido com o teste de emergência, e suas avaliações realizadas, diariamente, a partir do surgimento das primeiras plântulas normais até o $28^{\circ}$.

Preliminarmente, os dados foram submetidos à análise de variância, a fim de se verificar a existência de variabilidade genética entre as populações, sendo que suas médias foram agrupadas pelo teste de Scott \& Knott, a 5\% de probabilidade. Utilizou-se o software GENES - versão 2005 (Cruz, 2001) para realizar as análises estatísticas.

Foi utilizada a análise multivariada, aplicando-se as técnicas de agrupamento e de variáveis canônicas. Na técnica de agrupamento, foi utilizada a distância generalizada de Mahalanobis (Mahalanobis, 1936) como medida de dissimilaridade, e na delimitação dos grupos, o método de otimização de Tocher, citado por Rao (1952), adotando-se o critério de que a média das medidas de divergência dentro de cada grupo deve ser menor que as distâncias médias entre quaisquer grupos.

Após a formação inicial dos grupos, utilizou-se a metodologia anterior para subdividir o grupo 1, que concentrou um maior número de populações. $\mathrm{Na}$ análise de variáveis canônicas, a diversidade genética foi evidenciada por meio de gráficos cartesianos, sendo os eixos representados pelas primeiras variáveis canônicas (Cruz et al., 2004). Adicionalmente, foi quantificada a contribuição relativa dos caracteres para a divergência genética, por meio das distâncias generalizadas de Mahalanobis, utilizando o critério proposto por Singh (1981).

\section{RESULTADOS E DISCUSSÃO}

A análise de variância revelou diferença significativa entre as médias dos acessos, a $5 \%$ de probabilidade, pelo teste $\mathrm{F}$, para comprimento da raiz, germinação, IVE, número de folhas e massa da matéria seca de plântula. Nas variáveis altura da parte aérea e sobrevivência, não foi encontrado efeito significativo, pelo teste F.

Por meio da comparação de médias (Tabela 2), verifica-se que apenas cinco, das 24 populações, apresentaram germinação acima de $50 \%$ (populações $4 ; 8 ; 19 ; 20$ e 22, com valores médios de 61,$0 ; 60,0 ; 60,5 ; 84,0$ e $60,5 \%$, respectivamente), indicando que esses materiais são promissores para trabalhos futuros de melhoramento. As populações que apresentaram maiores índices de velocidade de emergência foram também aquelas com germinação acima de 50\%, destacando-se a população 20 (Tabela 2).

Segundo Tekrony \& Egli (1991), o vigor das plântulas, observado no campo pela habilidade da semente em emergir e crescer rápida e vigorosamente é um fator que pode influenciar na produtividade das culturas. De acordo com Melo et al. (2000), a médio e longo prazos, o melhoramento genético de Passiflora spp. deverá selecionar plantas nas populações, considerando a taxa de germinação das sementes, além de outras características agronômicas. 
Com base na magnitude relativa de valores $\mathrm{D}^{2}$,verificase, por meio do método de agrupamento de Tocher, a formação de quatro grupos distintos, nos quais se percebe uma concentração de populações no primeiro grupo (Tabela 3). No grupo 1, composto por 16 populações, utilizou-se o mesmo procedimento inicial na formação dos grupos a partir das 24 populações, sendo este grupo reagrupado em 9 subgrupos (Tabela 3).

As populações $2 ; 4 ; 8 ; 19 ; 22$ e 24 foram agrupadas no mesmo grupo (Tabela 3). Destas, a 4; 8; 19 e 22 apresentaram germinação acima de $50 \%$, juntamente com a população 20 , que ficou só em um grupo. Apesar de ter apresentado geminação acima de $50 \%$, a população 20 destacou-se em germinação, IVE e massa da matéria seca de plântula (Tabela 2).

Como o maracujazeiro é uma planta alógama, a escolha correta dos genitores e o planejamento dos cruzamentos podem maximizar a utilização de genes favoráveis ou explorar a heterose por meio de cruzamentos entre indivíduos com boas características agronômicas e com certo grau de divergência genética, possibilitando a obtenção de variedades superiores.

Em relação à contribuição relativa de cada característica para a diversidade genética entre as populações (Tabela 4), com base no critério proposto por Singh (1981), verifica-se que, para as 24 populações avaliadas, tem-se, em ordem decrescente de contribuição, as características porcentagem de germinação, número de folhas, IVE, porcentagem de sobrevivência, altura da parte aérea, massa da matéria seca e comprimento da raiz. Assim, as características porcentagem de germinação, número de folhas e IVE contribuíram com $92,6 \%$ da distribuição total, sendo consideradas importantes no presente estudo. $\mathrm{O}$ comprimento da raiz e massa da matéria seca apresentaram as menores estimativas de S.j (em que S é a medida da importância relativa para cada variável j para o estudo da diversidade genética), não se revelando importantes para a avaliação da divergência geral entre as progênies.

A porcentagem de germinação contribuiu com $55,6 \%$ da divergência, e, como relatado anteriormente, o melhoramento genético deverá selecionar plantas considerando a germinação de sementes, além de outras características agronômicas. Portanto, no presente estudo, a porcentagem de germinação foi a característica de maior importância.

De modo geral, quando o número de progênies é relativamente grande e o interesse é avaliar a divergência genética entre as mesmas no espaço global, a utilização da dispersão gráfica, juntamente com o método de agrupamento, considerando os dados originais, apresenta-se de grande importância no estudo de relacionamento entre as progênies (Xavier, 1996).

Quando se estuda a diversidade genética pelo método das variáveis canônicas, tem-se como propósito a identificação de genótipos similares em gráficos de dispersão bi ou tridimensional, possibilitando simplificar a interpretação dos resultados. A viabilidade de sua interpretação está restrita à concentração da variabilidade entre as primeiras variáveis, geralmente acima de $80 \%$ (Cruz et al., 2004). No presente estudo, verifica-se que as duas primeiras variáveis explicam $84,44 \%$ da variação total. Portanto, justifica-se a utilização da análise de variáveis canônicas, por proporcionarem uma simplificação estrutural dos dados.

As populações 2; 4; 8; 19 e 22 apresentaram posições bem similares, formando um grupo, ao passo que as populações 12 e 20 foram as mais dissimilares, formando um grupo cada (Figura 1). A população 12 foi a que apresentou os piores resultados médios para todas as características avaliadas (Tabela 2), não sendo indicada para futuros trabalhos de melhoramento. As demais foram similares, ficando agrupadas em um único grupo. A população 20 apresentou considerável divergência das demais (Tabela 3, Figura 1), com alta germinação, massa da matéria seca da planta e IVE, sendo, portanto, indicada em cruzamentos visando à obtenção de progênies com alta heterose e alta germinação e vigor.

A dispersão das populações por meio das variáveis canônicas apresentou comportamento semelhante ao agrupamento de Tocher. Somente a população 24, que tinha sido classificada no grupo 2 por meio do método de Tocher, foi classificada pelas variáveis canônicas no grupo 1 .

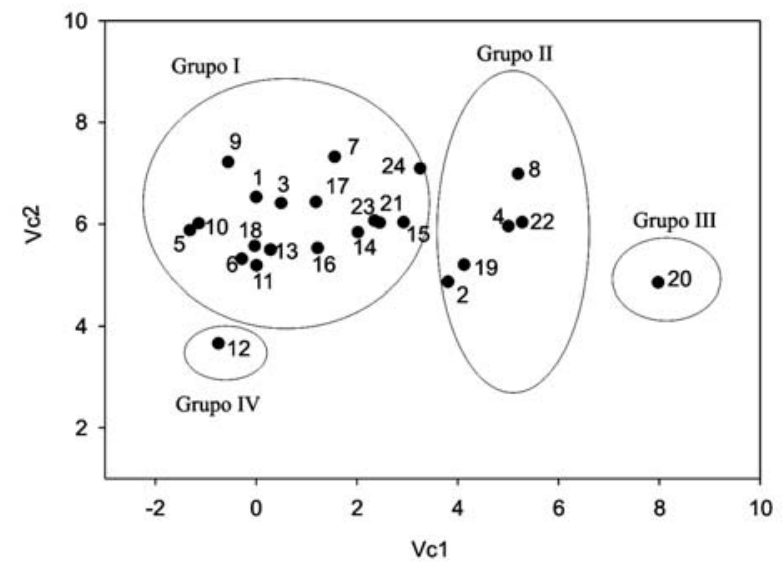

FIGURA 1 - Dispersão gráfica de escores de 24 populações de maracujazeiro-amarelo, em relação às duas primeiras variáveis canônicas ( $\mathrm{VC} 1$ e VC2).

TABELA 1 - Caracterização, ascendência e procedência de 24 populações de maracujazeiro- amarelo. Viçosa (MG), 2003

\begin{tabular}{cccc}
\hline Tratamento & Caracterização & Ascendência & Procedência \\
\hline 1 & Progênie de meios-irmãos & Sul Brasil & Viçosa-MG \\
2 & Progênie de meios-irmãos & (CS9 x P3) & Viçosa-MG \\
3 & Progênie de meios-irmãos & CS9 & Viçosa-MG \\
4 & Progênie de meios-irmãos & Planta 1 & Campos dos Goytacazes-RJ \\
5 & Progênie de meios-irmãos & (CY6 x Sul Brasil) & Viçosa-MG \\
6 & Progênie de meios-irmãos & CY6 & Viçosa-MG \\
7 & Progênie de meios-irmãos & (CY6 x C16) & Viçosa-MG \\
8 & Progênie de meios-irmãos & (CT8 x Sul Brasil) & Viçosa-MG \\
9 & Progênie de meios-irmãos & (CT8 x P2) & Viçosa-MG \\
10 & Progênie de meios-irmãos & (CT8 x P3) & Viçosa-MG \\
11 & Progênie de meios-irmãos & (PA CT8) & Viçosa-MG \\
12 & Progênie de meios-irmãos & (CT8 x P1) & Viçosa-MG \\
13 & Progênie de meios-irmãos & CL6 & Viçosa-MG \\
14 & Progênie de meios-irmãos & P1 & Viçosa-MG \\
15 & Progênie de meios-irmãos & P3 & Viçosa-MG \\
16 & Progênie de meios-irmãos & T3 & Viçosa-MG \\
17 & Progênie de meios-irmãos & T12 & Viçosa-MG \\
18 & Progênie de meios-irmãos & T14 & Viçosa-MG \\
19 & Progênie de meios-irmãos & T16 & Viçosa-MG \\
20 & Progênie de meios-irnãos & T28 & Viçosa-MG \\
21 & Progênie de meios-irnãos & & Norte do Rio de Janeiro \\
22 & Progênie de meios-irmãos & & Norte do Rio de Janeiro \\
23 & Cultivar IAC 273 & & Campinas-SP \\
24 & Cultivar IAC 277 & & Campinas-SP \\
\hline
\end{tabular}

Rev. Bras. Frutic., Jaboticabal - SP, v. 30, n. 1, p. 197-201, Março 2008 
TABELA 2 - Agrupamento de médias das características de 24 populações segregantes de maracujazeiroamarelo $\left.{ }^{*}\right)$

\begin{tabular}{|c|c|c|c|c|c|}
\hline Tratamentos & $\mathrm{CR}^{1 /}$ & $G(\%)^{/ 2}$ & $\mathrm{IVE}^{/ 3}$ & $\mathrm{NF}^{/ 4}$ & $\mathrm{MSP}^{/ 5}$ \\
\hline 1 & $5,343 \mathrm{~b}$ & $10,00 \mathrm{e}$ & $0,323 \mathrm{~d}$ & $2,705 \mathrm{a}$ & $0,168 \mathrm{c}$ \\
\hline 2 & $6,603 a$ & $45,50 \mathrm{c}$ & $1,238 \mathrm{c}$ & $2,768 \mathrm{a}$ & $0,575 \mathrm{~b}$ \\
\hline 3 & $6,328 \mathrm{a}$ & $14,00 \mathrm{e}$ & $0,610 \mathrm{~d}$ & $2,828 \mathrm{a}$ & $0,330 \mathrm{c}$ \\
\hline 4 & $6,713 \mathrm{a}$ & $61,00 \mathrm{~b}$ & $1,568 \mathrm{~b}$ & $3,085 \mathrm{a}$ & $0,628 \mathrm{~b}$ \\
\hline 5 & $5,793 \mathrm{a}$ & $4,80 \mathrm{e}$ & $0,168 \mathrm{~d}$ & $2,608 \mathrm{~b}$ & $0,090 \mathrm{c}$ \\
\hline 6 & $5,838 \mathrm{a}$ & $19,00 \mathrm{~d}$ & $0,445 \mathrm{~d}$ & $2,638 \mathrm{a}$ & $0,390 \mathrm{c}$ \\
\hline 7 & 6,478 a & $21,00 \mathrm{~d}$ & $0,525 \mathrm{~d}$ & $3,063 \mathrm{a}$ & $0,178 \mathrm{c}$ \\
\hline 8 & $7,635 \mathrm{a}$ & $60,00 \mathrm{~b}$ & $1,780 \mathrm{~b}$ & $3,313 \mathrm{a}$ & $0,653 \mathrm{~b}$ \\
\hline 9 & $5,345 \mathrm{~b}$ & $4,50 \mathrm{e}$ & $0,205 \mathrm{~d}$ & $2,908 \mathrm{a}$ & $0,078 \mathrm{c}$ \\
\hline 10 & $6,303 \mathrm{a}$ & $7,00 \mathrm{e}$ & $0,190 \mathrm{~d}$ & $2,715 \mathrm{a}$ & $0,290 \mathrm{c}$ \\
\hline 11 & $6,810 \mathrm{a}$ & $15,00 \mathrm{e}$ & $0,358 \mathrm{~d}$ & $2,595 \mathrm{a}$ & $0,268 \mathrm{c}$ \\
\hline 12 & $4,575 \mathrm{~b}$ & $1,495 \mathrm{e}$ & $0,143 \mathrm{~d}$ & $1,813 \mathrm{~b}$ & $0,060 \mathrm{c}$ \\
\hline 13 & $6,073 \mathrm{a}$ & $21,00 \mathrm{~d}$ & $0,420 \mathrm{~d}$ & $2,700 \mathrm{a}$ & $0,328 \mathrm{c}$ \\
\hline 14 & $5,873 \mathrm{a}$ & $31,00 \mathrm{~d}$ & $0,655 \mathrm{~d}$ & $2,658 \mathrm{a}$ & $0,590 \mathrm{~b}$ \\
\hline 15 & 6,488 a & $40,00 \mathrm{c}$ & $1,080 \mathrm{c}$ & $2,963 \mathrm{a}$ & $0,413 \mathrm{c}$ \\
\hline 16 & $6,678 a$ & $27,50 \mathrm{~d}$ & $0,640 \mathrm{~d}$ & $2,785 a$ & $0,503 \mathrm{~b}$ \\
\hline 17 & 6,303 a & $18,00 \mathrm{~d}$ & $0,483 \mathrm{~d}$ & $2,805 \mathrm{a}$ & $0,343 \mathrm{c}$ \\
\hline 18 & $5,750 \mathrm{a}$ & $19,50 \mathrm{~d}$ & $0,498 \mathrm{~d}$ & $2,695 \mathrm{a}$ & $0,385 \mathrm{c}$ \\
\hline 19 & $6,748 \mathrm{a}$ & $60,50 \mathrm{~b}$ & $1,520 \mathrm{~b}$ & $3,010 \mathrm{a}$ & $0,868 \mathrm{a}$ \\
\hline 20 & $6,818 \mathrm{a}$ & $84,00 \mathrm{a}$ & $2,698 \mathrm{a}$ & $3,073 \mathrm{a}$ & $1,033 \mathrm{a}$ \\
\hline 21 & $6,260 \mathrm{a}$ & $39,00 \mathrm{c}$ & $1,055 \mathrm{c}$ & $2,850 \mathrm{a}$ & $0,445 \mathrm{c}$ \\
\hline 22 & $6,710 \mathrm{a}$ & $60,50 \mathrm{~b}$ & $1,593 \mathrm{~b}$ & $3,005 \mathrm{a}$ & $0,620 \mathrm{~b}$ \\
\hline 23 & $6,210 \mathrm{a}$ & $30,50 \mathrm{~d}$ & $0,773 \mathrm{~d}$ & $2,925 \mathrm{a}$ & $0,428 \mathrm{c}$ \\
\hline 24 & $6,923 \mathrm{a}$ & $37,50 \mathrm{c}$ & $1,188 \mathrm{c}$ & $3,100 \mathrm{a}$ & $0,458 \mathrm{c}$ \\
\hline
\end{tabular}

1/Comprimento da raiz; 2/\%Germinação; 3/IVE; 4/Número de folhas e 5/ Massa da matéria seca de plântula.

(*) Médias seguidas pela mesma letra, nas colunas, pertencem ao mesmo agrupamento, pelo teste de Scott e Knott, a 5\% de probabilidade.

TABELA 3 - Grupos de similaridade genética entre 24 populações de maracujazeiro-amarelo estabelecidos pelo método de Tocher, baseado na distância generalizada de Mahalanobis.

\begin{tabular}{ll}
\hline Grupo & Progênies \\
\hline 1.1 & $6-18-13-1$ \\
1.2 & $15-21$ \\
1.3 & $3-17-16$ \\
1.4 & $5-10$ \\
1.5 & 9 \\
1.6 & 11 \\
1.7 & 7 \\
1.8 & 23 \\
1.9 & 14 \\
2 & $4-22-8-19-2-24$ \\
3 & 20 \\
4 & 12 \\
\hline
\end{tabular}

TABELA 4 - Estimativas da contribuição relativa de cada característica (S.j) para a divergência genética entre as progênies de maracujazeiro-amarelo, com base na partição do total de $\mathrm{D}^{2}$.

\begin{tabular}{lcc}
\hline \multicolumn{1}{c}{ Variável } & \multicolumn{2}{c}{ Contribuição Relativa } \\
\cline { 2 - 3 } & $\mathrm{S} . \mathrm{j}$ & $\%$ \\
\hline \%Germinação & 2489,706 & 55,6 \\
Número de folhas & 838,524 & 18,7 \\
IVE & 814,014 & 18,2 \\
\%Sobrevivência & 126,370 & 2,8 \\
Altura da parte aérea & 117,648 & 2,6 \\
Massa da matéria seca & 74,240 & 1,7 \\
Comprimento da raiz & 14,275 & 0,3 \\
\hline
\end{tabular}

\section{CONCLUSÕES}

1-Das características avaliadas, as que mais contribuíram para a divergência genética foram porcentagem de germinação, número de folhas e IVE.

2-A população 20 pode ser recomendada para hibridação com as outras populações devido à sua alta divergência e também às altas taxas de germinação e vigor de sementes.

\section{REFERÊNCIAS}

ALEXANDRE, R.S.; WAGNER JÚNIOR, A.; NEGREIROS, J.R.S.; PARIZOTTO, A.; BRUCKNER, C.H. Germinação de sementes de genótipos de maracujazeiro. Pesquisa Agropecuária Brasileira, Brasília, v.39, n.12,p. 1239-1245, 2004.

AKAMINE, E.K.; BEUMONT, J.H.; BOWERS, F.A.I.; HAMILTON, R.A.; NISHIDA, T.; SHERMAN, G.D.; SHOJI, K.; STOREY, W.B. Passion fruit culture in Hawaii. Hawaii: University of Hawaii, 1956.35p. (Extension Circular, 245).

CARVALHO, L.P. de; LANZA, M.A.; FALLIERI, J.; SANTOS, J.W. dos. Análise da divergência genética entre acessos de banco ativo de germoplasma de algodão. Pesquisa Agropecuária Brasileira, Brasília, v. 38, n. 10, p. 1149-1155, 2003.

CRUZ, C.D. Programa GENES - versão Windows: aplicativo computacional em genética e estatística. Viçosa: Universidade Federal de Viçosa, 2001. 648 p.

CRUZ, C.D., REGAZZI, A.J., CARNEIRO, P.C.S. Modelos biométricos aplicados ao melhoramento genético. Viçosa: Universidade Federal de Viçosa, 2004. v. 3. 480 p.

CUNHA, M.A.P. da; BARBOSA, L.V.; JUNQUEIRA, N.T.V. Espécies de maracujazeiro. In: LIMA, A. de A. (Ed. Técnico). Maracujá - Produção: aspectos técnicos. Brasília: Embrapa Informação tecnológica, 2002. p. 15-24. (Frutas do Brasil, 15).

DIAS, D.C.F.S.; MARCOS FILHO, J. Testes de vigor baseados na permeabilidade das membranas celulares: I. Condutividade elétrica. Informativo Abrates, Brasília, v.5, p.26-33, 1995.

LIMA, A. de A. Introdução. In: LIMA, A. de A. (Ed.). Maracujá produção: aspectos técnicos. Brasília: Embrapa Informação tecnológica, 2002. p. 9. (Frutas do Brasil, 15).

LUNA, J.V.U. Instruções para a cultura do maracujá. Salvador: EPABA, 1984.25 p. (Circular Técnica, 7).

MAGUIRE, J.D. Speed of germination aid in selection and evaluation for emergence and vigour. Crop Science, Madison, v.2,p.176-177, 1962. 
MAHALANOBIS, P.C. On the generalized distance in statistics. Proceedings of the National Institute of Science of India, New Delhi, v.2, p. 49-55, 1936.

MELO, A.L.; OLIVEIRA, J.C.; VIEIRA, R.D. Superação de dormência em sementes de Passiflora nitida H. B. K. com hidróxido de cálcio, ácido sulfúrico e ácido giberélico. Revista Brasileira de Fruticultura, Jaboticabal, v.22, p.260-263, 2000.

PANDEY, G.; DOBHAL, V.K. Multivariate analysis in taro (Colocasia esculenta L.). Indian Journal of Genetics \& Plant breeding, New Delhi, v. 57, n. 3, p. 262-265, 1997.

PRETE, C.E.C.; GUERRA, E.P. Qualidade fisiológica das sementes. In: DESTRO, D.; MONTALVÁN, R. Melhoramento genético de plantas. Londrina: UEL, 1999. p. 661-676.

RAO, R.C. Advanced statistical methods in biometric research. New York: Jonh Wiley and Sons, 1952. 390 p.
SAMAL, K.M.; JAGADEV, P.N. Genetic divergence among chickpea cultivars. Indian Journal of Genetics \& Plant breeding, New Delhi, v. 56, n. 1, p. 86-88, 1996.

SINGH, D. The relative importance of characters affecting genetic divergence. The Indian Journal of Genetic and Plant Breeding, New Delhi, v. 41, n. 1, p. 237-245, 1981.

SOUZA, J. da S.; CARDOSO, C.E.L.; LIMA, A. de A.; COELHO, E.F. Aspectos socioeconômicos. In: LIMA, A. de A. (Ed. Técnico) Maracujá produção: aspectos técnicos. Brasília: Embrapa Informação tecnológica, 2002. p. 10. (Frutas do Brasil, 15).

TEKRONY, M.D.; EGLI, D.B. Relationship of seed vigour to crop yield: a review. Crop Science, Madson, v. 31, p. 816-822, 1991.

XAVIER, A. Aplicação de análise multivariada da diversidade genética no melhoramento de Eucalyptus spp. 1996. 126 f. Tese (Doutorado em Ciência Florestal) - Departamento de Engenharia Florestal, Universidade Federal de Viçosa, Viçosa- MG, 1996. 